\title{
PENGARUH KUALITAS LAYANAN TERHADAP KEPUASAN KONSUMEN KOPERASI KARYAWAN SEJAHTERA UNIVERSITAS MUHAMMADIYAH PURWOKERTO
}

\author{
Eka Yuliana \\ Fakultas Ekonomi Universitas Muhammadiyah Purwokerto \\ Muchammad Agung Miftahudin \\ Fakultas Ekonomi Universitas Muhammadiyah Purwokerto
}

\begin{abstract}
This research aimed analyze the independent variable effect (tangibles, reliability, responsiveness, assurance, and empathy) towards the dependent variable (consumers satisfactory) in Koperasi Karyawan Sejahtera University of Muhammadiyah Purwokerto.

In this research, the researcher did the sampling by distributing questionnaire. The total of sample was 120 respondents. The analysis don was by double regression analysis.

The t test showed that the independent variable of tangibles, reliability, responsiveness, assurance, and empathy affected partially towards the dependent variable consumers' satisfactory, while the variable of reliabilty and responsiveness did not affect on consumers' satisfactory in a whole. Based on the elasticity test, the variable of tangibles affected dominantly toward consumers' satisfactory.
\end{abstract}

Keywords: tangibles, reliability, responsiveness, assurance, and empathy, consumers' satisfactory.

\begin{abstract}
ABSTRAK
Penelitian ini bertujuan untuk menganalisis pengaruh variabel independen (tangibles, reliability, responsiveness, assurance, dan empathy) terhadap variabel dependen (kepuasan konsumen) di Koperasi Karyawan Sejahtera Universitas Muhammadiyah Purwokerto.

Peneliti menggunakan sampel melalui penyebaran quisioner dengan total sampel sebanyak 120 responden. Data yang didapatkan dianalisis dengan menggunakan analisis regresi berganda.

Hasil uji $\mathrm{t}$ menunjukkan bahwa variabel independen (tangibles, reliability, responsiveness, assurance, dan empathy) berpengaruh secara parsial terhadap variabel dependen (kepuasan konsumen), semnetara variabel reliabilty dan responsiveness tidak berpengaruh terhadap kepuasan konsumen. Berdasarkan elasticity test, variabel tangibles berpengaruh sangat kuat terhadap kepuasan konsumen.
\end{abstract}

Kata Kunci: tangibles, reliability, responsiveness, assurance, dan empathy, kepuasan konsumen. 


\section{PENDAHULUAN}

\section{A. Latar Belakang}

Keanekaragaman konsumen dalam membeli suatu produk atau jasa dipengaruhi oleh beberapa dimensi yang menyangkut masalah kualitas layanan, yaitu tangibles (berwujud), reliability (keandalan), responsiveness (tanggapan), assurance (jaminan), empathy (perhatian), Tjiptono (2002). Hal tersebut sangat penting dan diperlukan bagi setiap perusahaan. Dikarenakan hal ini dapat memberikan umpan balik dan masukan bagi keperluan pengembangan dan implementasi strategi peningkatan kepuasan konsumen.

Setiap konsumen mempunyai tingkatan dan keinginan kebutuhan sendiri. Sehingga, tiap konsumen mempunyai kepuasan sendiri. Kepuasan tersebut juga akan memberikan beberapa manfaat antara lain hubungan antara perusahaan dan para konsumennya menjadi harmonis, dapat mendorong tercapainya loyalitas pelanggan, membentuk suatu rekomendasi dari mulut ke mulut (word of mouth) yang menguntungkan bagi perusahaan, reputasi perusahaan menjadi baik dimata konsumen, serta laba yang diperoleh dapat meningkat.

Koperasi merupakan suatu badan usaha yang beranggotakan orang atau seseorang atau badan hukum koperasi dengan melandaskan kegiatannya berdasarkan prinsip-prinsip koperasi, sekaligus sebagai gerakan ekonomi rakyat yang berdasarkan atas azas kekeluargaan. Hal ini berarti bahwa masing-masing anggota sadar dan memiliki semangat untuk selalu bekerja sama dan bertanggung jawab secara bersama-sama tanpa memikirkan kepentingan diri sendiri untuk kepentingan bersama.

Koperasi Karyawan Sejahtera Universitas Muhammadiyah Purwokerto atau (Kopkar Sejahtera UMP) adalah Koperasi yang ada di UMP yang berdiri tanggal 1 Januari 2002 dengan nomor Badan Hukum 89/BH/K/11- 15/II/2002 dan berkantor di komplek Kampus Universitas Muhammadiyah Purwokerto, kantor tersebut sekaligus sebagai tempat usaha. Kopkar Sejahtera Universitas Muhammadiyah Purwokerto beralamat di Jl. Raya Dukuhwaluh PO. Box. 202 Kecamatan Kembaran Kabupaten Banyumas, Jawa Tengah, telpon (0281) 636751 pesawat 217, atau alamat website http://www.geocities.com/kopkarsejahtera. Kopkar Sejahtera Universitas Muhammadiyah Purwokerto memiliki beberapa unit layanan yakni simpan pinjam, toko (minimarket), serta fotocopy.

Penelitian ini merupakan replikasi dari penelitian yang telah dilakukan oleh Soegiono dan Suprihadi (2007) yang mengatakan bahwa ada pengaruh kualitas layanan terhadap kepuasan konsumen. Penelitian ini mengambil obyek Koperasi Karyawan Sejahtera UMP dan unit usaha yang diteliti yaitu unit usaha Fotocopy dan Minimarket. Sedangkan penelitian sebelumnya menggunakan obyek Koperasi Karyawan UBAYA dan unit usahanya simpan pinjam. Alasan peneliti memilih Koperasi Karyawan Sejahtera UMP pada unit usaha Fotocopy dan Minimarket adalah ingin mengetahui lebih dalam tentang pelayanan yang diberikan Karyawan Fotocopy dan Minimarket Koperasi Karyawan Sejahtera UMP. Berdasarkan uraian diatas, maka penulis tertarik untuk mengadakan penelitian dengan judul "Pengaruh Kualitas Layanan Terhadap Kepuasan Konsumen Koperasi Sejahtera Universitas Muhammadiyah Purwokerto".

\section{B. Tujuan Penelitian}

(1) Untuk menganalisis pengaruh kualitas layanan terhadap kepuasan consume secara parsial yang ada di Koperasi karyawan Sejahtera Universitas Muhammadiyah Purwokerto .(2) Untuk menganalisis pengaruh kualitas layanan secara simultan terhadap kepuasan konsumen Koperasi Karyawan Sejahtera Universitas Muhammadiyah Purwokerto. (3) Untuk menganalisis kualitas layanan yang paling dominan terhadap kepuasan konsumen Koperasi Karyawan Sejahtera Universitas Muhammadiyah Purwokerto. 


\section{Kerangka Pemikiran}

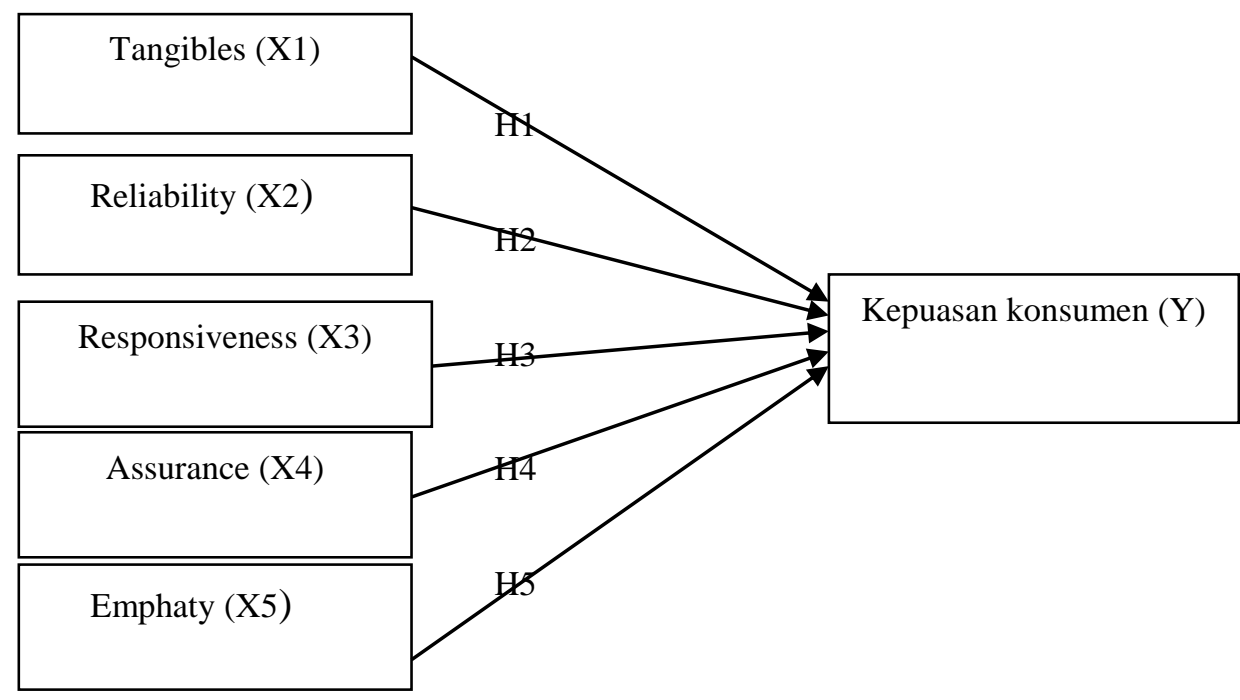

Gambar 1. Kerangka Pemikiran

\section{HIPOTESIS}

H1 : Variabel kualitas layanan yang meliputi tangibles (berwujud), reliability keandalan), responsiveness (tanggapan), assurance (jaminan) dan empathy (perhatian) berpengaruh secara parsial terhadap kepuasan konsumen pada Koperasi Karyawan Sejahtera UMP.

$\mathrm{H} 2$ : Variabel kualitas layanan yang meliputi tangibles (berwujud), reliability keandalan), responsiveness (tanggapan), assurance (jaminan) dan empathy (perhatian) berpengaruh secara simultan terhadap kepuasan konsumen pada Koperasi Karyawan Sejahtera UMP.

H3 : Variabel kualitas layanan yang terdiri dari tangibles (berwujud), reliability (keandalan), responsiveness (tanggapan), assurance (jaminan) dan empathy (perhatian) yang memiliki pengaruh paling dominan terhadap kepuasan konsumen adalah variabel reliability

\section{METODE PENELITIAN}

Jenis metode penelitian yang digunakan dalam penelitian ini adalah penelitian survey, yaitu semua informasi yang dikumpulkan dari responden dengan menggunakan kuesioner. Objek penelitian ini adalah Konsumen Koperasi Karyawan Sejahtera Universitas Muhammadiyah Purwokerto. Teknik pengambilan sampel yang akan digunakan adalah purposive sampling yaitu pengambilan sampel yang didasarkan pada pertimbangan untuk menyesuaikan dengan kriteria penelitian agar dapat meningkatkan ketepatan sampel (Sugiyono, 2009). Kriteria tersebut yaitu dari kalangan Dosen/Karyawan, mahasiswa dan masyarakat umum yang pernah datang untuk bertransaksi ke minimarket maupun datang untuk fotocopy di Koperasi Karyawan Sejahtera UMP. Penelitian ini menggunakan regresi linier berganda, uji F dan uji t.

\section{A. Definisi Operasional}

\section{Pengertian kepuasan konsumen}

Kepuasan konsumen(Y) merupakan tingkat perasaan seseorang setelah membandingkan kinerja (hasil) yang dirasakan dibandingkan dengan harapannya, (Kolter 2002). 
Indikator - indikator yang akan diteliti pada variabel ini adalah :

1) Pelayanan yang diberikan karyawan fotocopy dan minimarket sesuai dengan harapan konsumen

2) Secara keseluruhan pelayanan yang diberikan karyawan fotocopy dan minimarket memuaskan

3) Pelanggan ingin melakukan pembelian ulang

4) Merekomendasikan kepada orang lain

\section{PengertianVariabel Berwujud (Tangibles)}

Berwujud (X1) adalah penampilan dari fasilitas fisik Koperasi (unit usaha fotocopy dan minimarket), sarana dan prasarana, dan daya tarik karyawan. Semakin baik ketiga hal tersebut maka kepuasan akan meningkat, Lupiyoadi (2001: 148).

Indikator - indikator yang akan diteliti pada variabel ini adalah :

1) Kondisi gedung atau lingkungan nyaman dan bersih

2) Peralatan yang dimiliki representatif

3) Akses tempat yang mudah dijangkau dan strategis

4) Peraturan dan penataan ruangan yang nyaman

\section{Pengertian Variabel Keandalan (Reliability)}

Keandalan (X2) adalah kemampuan untuk memberikan jasa secara tepat dan akurat, hal tersebut dapat mengoptimalkan kualitas pelayanan koperasi, terutama di unit atau usaha fotocopy dan minimarket dimana semakin tinggi kemampuan Koperasi dalam memberikan pelayanan yang terbaik maka semakin tinggi tingkat kepuasan konsumen, Lupiyoadi (2001: 148).

Indikator - indikator yang akan diteliti pada variabel ini adalah :

1) Karyawan fotocopy dan minimarket dapat melayani konsumen dengan baik

2) Karyawan fotocopy dan minimarket dapat diandalkan dan dipercaya

3) Pelayanan yang ramah kepada konsumen

4) Karyawan fotocopy dan minimarket bersikap simpatik kepada konsumen

5) Karyawan dalam melayani konsumen cepat

\section{Pengertian Variabel Ketanggapan (Responsiveness)}

Ketanggapan (X3) adalah keinginan karyawan untuk membantu konsumen dan memberikan pelayanan yang tepat. Pengaruh ketanggapan yang besar akan menimbulkan kepuasan konsumen yang besar pula, Lupiyoadi (2001: 148). 
Indikator - indikator yang akan diteliti pada variabel ini adalah :

1) Karyawan fotocopy maupun minimarket dalam melayani cepat dan tanggap

2) Karyawan fotocopy dan minimarket mampu berkomunikasi dengan baik kepada konsumen

3) Penyampaian yang jelas tentang barang atau jasa kepada konsumen

4) Karyawan yang selalu bersedia membantu konsumen

\section{Pengertian Variabel Jaminan (Assurance)}

Jaminan (X4) adalah pengetahuan dan kesopanan karyawan serta kemampuan mereka untuk memberi rasa aman dan menjamin kredibilitas Koperasi. Pengaruh variabel jaminan yang meningkat akan menyebabkan kepuasan konsumen menjadi semakin tinggi, Lupiyoadi (2001 : 148).

Indikator - indikator yang akan diteliti pada variabel ini adalah :

1) Dalam melayani karyawan fotocopy dan minimarket bersifat sabar, ramah, dan sopan kepada konsumen

2) Karyawan memiliki pengetahuan dan kemampuan yang cukup sesuai dengan bidang pekerjaanya

3) Tidak membanding-bandingkan konsumen yang satu dengan yang lain

4) Perasaan aman sewaktu melakukan transaksi dengan karyawan penyedia jasa

\section{Pengertian Variabel Empati (empathy)}

Empati (X5) adalah kepedulian dan adanya perhatian yang dierikan secara individual kepada pelanggan. Kepuasan konsumen akan bertambah tinggi apabila dipengaruhi oleh variabel empati yang tinggi, Lupiyoadi (2001: 148).

Indikator - indikator yang akan diteliti pada penelitian ini adalah :

1) Karyawan memberikan pelayanan kepada konsumen dengan adil

2) Kesungguhan karyawan untuk memperhatikan konsumen

3) Karyawan menjalin hubungan interaktif dengan konsumen

4) Karyawan memahami kebutuhan spesifik para konsumen

5) Cepat dalam menanggapi keluhan konsumen

\section{HASIL PENELITIAN DAN PEMBAHASAN}

\section{A. Respon Rate}

Kuisioner yang disebarkan sejumlah 130 eksemplar sedangkan yang kembali dan dianalisis berjumlah 120 eksemplar 


\section{B. Uji Validitas}

Validitas instrument penelitian ini dapat dilihat dari nilai signifikansi. Jika nilai signifikansi kurang dari 0,05 maka item pertanyaan dikatakan valid, jika nilai signifikansi lebih dari 0,05 maka item pertanyaan tidak valid

\section{Uji Hipotesis}

\section{Hipotesis pertama}

Tabel 3.1 Hasil Uji T

Coefficients $^{\mathrm{a}}$

\begin{tabular}{|c|c|c|c|c|c|c|}
\hline \multirow{2}{*}{\multicolumn{2}{|c|}{ Model }} & \multicolumn{2}{|c|}{ Unstandardized Coefficients } & \multirow{2}{*}{$\begin{array}{c}\text { Standardized } \\
\text { Coefficients }\end{array}$} & \multirow[b]{2}{*}{$\mathrm{T}$} & \multirow[b]{2}{*}{ Sig. } \\
\hline & & $\mathrm{B}$ & Std. Error & & & \\
\hline \multirow[t]{6}{*}{1} & (Constant) & .664 & .275 & & 2.413 & .017 \\
\hline & tangibles & .321 & .052 & .473 & 6.146 & .000 \\
\hline & reliability & .005 & .076 & .006 & .063 & .950 \\
\hline & $\begin{array}{l}\text { Responsivine } \\
\text { ss }\end{array}$ & .055 & .062 & .072 & .888 & .376 \\
\hline & assurance & .198 & .068 & .229 & 2.925 & .004 \\
\hline & emphaty & .176 & .083 & .212 & 2.106 & .037 \\
\hline
\end{tabular}

a. Dependent Variable: kepuasan konsumen

a. Hipotesis pertama

Berdasarkan tabel 4.9 diketahui bahwa variabel tangibles memiliki nilai $t_{\text {hitung }}$ sebesar 6.146 sedangkan nilai $t_{\text {tabel }} 1,979$. Dengan demikian $t_{\text {hitung }}>t_{\text {tabel }}$ yaitu 6,146>1,979 serta nilai signifikan 0,000 kurang dari 0,05 artinya tangibles memiliki pengaruh signifikan terhadap kepuasan konsumen. Dengan demikian hipotesis pertama diterima.

b. Hipotesis kedua

Berdasarkan tabel 4.9 diketahui bahwa variabel reliability memiliki nilai $t_{\text {hitung }}$ sebesar 0,063 sedangkan nilai $t_{\text {tabel }} 1,979$. Dengan demikian $t_{\text {hitung }}<t_{\text {tabel }}$ yaitu $0,063<1,979$. Serta nilai signifikan 0,950 lebih dari 0,05 artinya reliability tidak berpengaruh secara signifikan terhadap kepuasan konsumen. Dengan demikian hipotesis kedua ditolak.

c. Hipotesis ketiga

Berdasarkan tabel 4.9 diketahui bahwa variabel responsiveness memiliki nilai $t_{\text {hitung }}$ sebesar 0,888 sedangkan nilai $t_{\text {tabel }} 1,979$ Dengan demikian $t_{\text {hitung }}>t_{\text {tabel }}$ yaitu $0,888>$ 1,979. Serta nilai signifikan 0,376 kurang dari 0,05 artinya responsiveness memiliki pengaruh signifikan terhadap kepuasan konsumen. Dengan demikian hipotesis ketiga ditolak.

d. Hipotesis keempat

Berdasarkan tabel 4.9 diketahui bahwa variabel assurance memiliki nilai thitung sebesar 2,925 sedangkan nilai $t_{\text {tabel }} 1,979$ Dengan demikian $t_{\text {hitung }}>t_{\text {tabel }}$ yaitu 2,925>1,979. Serta nilai signifikan 0,004 kurang dari 0,05 artinya assurance memiliki pengaruh signifikan terhadap kepuasan konsumen. Dengan demikian hipotesis keempat diterima. 


\section{e. Hipotesis kelima}

Berdasarkan tabel 4.9 diketahui bahwa variabel empathy memiliki nilai thitung sebesar 2,106 sedangkan nilai $t_{\text {tabel }} 1,979$ Dengan demikian $t_{\text {hitung }}>t_{\text {tabel }}$ yaitu 2,106>1,979 Serta nilai signifikan 0,037 kurang dari 0,05 artinya empathy memiliki pengaruh signifikan terhadap kepuasan konsumen. Dengan demikian hipotesis kelima diterima.

\section{Hipotesis Kedua}

\section{ANOVA}

\begin{tabular}{|ll|r|r|r|r|r|}
\hline Model & & Sum of Squares & Df & Mean Square & F & Sig. \\
\hline 1 & Regression & 24.794 & 5 & 4.959 & 23.755 & $.000^{\mathrm{a}}$ \\
& Residual & 23.797 & 114 & .209 & & \\
& 48.592 & 119 & & & \\
\hline
\end{tabular}

a. Predictors: (Constant), emphaty, responsiviness, tangibles, assurance, reliability

b. Dependent Variable: kepuasan konsumen

Uji anova atau uji $\mathrm{F}$ menunjukkan bahwa nilai $\mathrm{F}_{\text {hitung }}$ pada model penelitian diketahui 23,755 sedangkan $F_{\text {tabel }}$ sebesar 1,979. Sehingga diketahui $F_{\text {hitung }}>F_{\text {tabel }}$ yaitu 23,755 $>1,979$ dengan taraf signifikan sebesar 0,000 lebih kecil dari 0,05 yang menunjukkan bahwa tangibles, reliability, responsiveness, assurance dan empathymempunyai nilai signifikan secara keseluruhan terhadap kepuasan konsumen, sehingga hipotesis diterima.

\section{Hipotesis ketiga}

\begin{tabular}{|c|c|c|c|}
\hline Variabel & Rata-rata & Koefisien & Elastisitas \\
\hline $\mathrm{E}_{\mathrm{I}}$ & 14,41 & 0,321 & 0,322 \\
$\mathrm{E}_{2}$ & 17,76 & 0,005 & 0,006 \\
$\mathrm{E}_{3}$ & 15,07 & 0,055 & 0,057 \\
$\mathrm{E}_{4}$ & 14,92 & 0,198 & 0,203 \\
$\mathrm{E}_{5}$ & 18,88 & 0,176 & 0,229 \\
$\mathrm{Y}$ & 14,49 & & - \\
\hline
\end{tabular}

Hasil elastisitas menunjukan bahwa $E_{1}>E_{2}, E_{3}, E_{4}, E_{5}$ berarti variabel berwujud (tangibles) merupakan komponen yang paling berpengaruh besar/paling dominan terhadap kepuasan konsumen pada Koperasi Karyawan Sejahtera UMP.

Jadi hipotesis yang menyatakan bahwa variabel kehandalan (reliability) berpengaruh paling dominan terhadap kepuasan konsumen Koperasi Karyawan Sejahtera UMP ditolak.

\section{PEMBAHASAN}

Berdasarkan uji elastisitas menunjukan bahwa variabel berwujud (tangibles) merupakan komponen yang paling berpengaruh paling dominan terhadap kepuasan konsumen pada Koperasi Karyawan Sejahtera UMP. Artinya tangibles/penampilan fisik Koperasi yang meliputi kondisi 
gedung, lingkungan yang bersih, tempat yang strategis, peralatan yang memadai dan kenyamanan ruangan sangat mempengaruhi para konsumen Koperasi

\section{KESIMPULAN DAN SARAN}

\section{A. Kesimpulan}

1. Uji parsial (uji t) membuktikan bahwa tangibles,assurance dan empathy berpengaruh secara signifikan terhadap kepuasan konsumen. Ini dapat dibuktikan dari nilai thitung lebih besar dari $t_{\text {tabel. }}$ Sedangkan variabel reliability dan responsiveness tidak berpengaruh signifikan terhadap kepuasan konsumen karena $t_{\text {tabel }}$ lebih besar dari $t_{\text {hitung. }}$.

2. Uji simultan (uji F) secara bersama-sama menunjukan bahwa nilai $F_{\text {hitung } 23,755}>F_{\text {tabel }}$ 1,979, maka dimensi kualitas layanan jasa berpengaruh positif dan signifikan terhadap kepuasan konsumen Koperasi Karyawan Sejahtera UMP.

3. Uji elastisitas menunjukan bahwa variabel berwujud (tangibles) merupakan komponen yang paling berpengaruh paling dominan terhadap kepuasan konsumen Koperasi Karyawan Sejahtera UMP.

\section{B. Saran}

\section{Saran untuk Koperasi Karyawan Sejahtera UMP}

Berdasarkan hasil penelitian variabel reliability dan responsiveness kurang memiliki pengaruh terhadap kepuasan konsumen, maka disarankan agar Koperasi Karyawan Sejahtera UMP melakukan pelatihan terhadap karyawannya untuk menangani konsumen secara cepat dan tepat dalam memberikan pelayanan, membuat skedul kerja yang jelas sehingga dapat meningkatkan kualitas layanan yang diberikan.

2. Saran untuk penelitian mendatang

Diharapkan pada peneliti selanjutnya agar menambah variabel seperti acces (kemudahan hubungan), communications (komunikasi), dan understanding the customer (mengerti kebutuhan konsumen), karena diduga variabel tersebut memiliki pengaruh yang signifikan terhadap kepuasan konsumen Koperasi Karyawan Sejahtera UMP. Diharapkan untuk peneliti selanjutnya tidak boleh menggunakan kata dan di kuesionernya.

\section{DAFTAR PUSTAKA}

http://www.ump.ac.id/2009/06/06/kopkarsejahtera.

Kolter. 2002. Manajemen Pemasaran. Edisi Millenium. Prenhalindo. Jakarta.

Lupiyoadi, Rambat. 2001. Pemasaran Jasa. Jakarta. Salemba Empat.

Soegiono dan Suprihadi. 2007. Kualitas Layanan Terhadap Kepuasan Pelanggan Pada Koperasi Karyawan Universitas Surabaya. Jurnal. Vol. 6. No. 2.

Tjiptono, Fandy. 2002. Strategi Pemasaran. Edisi Kedua. Cetakan Keenam. Penerbit. Andy. Yogyakarta. 